\title{
Evaluation of two DNA amplification PCR tests for the diagnosis of Clostridium difficile infection
}

Rita Caldarelli',2, Anna Archenti ${ }^{3}$, Maria Cristina lbba $^{3}$, Sandra Giannotta ${ }^{3}$, Valeria Orioli $^{3}$, Cinzia Bovio ${ }^{2}$, Vittorio Molina', Pasquale Ferrante ${ }^{4}$

I Laboratorio Analisi, G.B. Mangioni Hospital, Lecco

2 Laboratorio Ricerca \& Sviluppo Neomed srl, Mazzo di Rho, MI

3 Laboratorio Microbiologia, Ospedale San Giuseppe, Milano

4 Dipartimento di Sanità Pubblica, Microbiologia, Virologia, Università degli Studi di Milano

Key words: Clostridium difficile, PCR, Diagnosis

Valutazione di due test di amplificazione di DNA mediante PCR per la diagnosi d'infezione da Clostridium difficile

SUMMARY

Introduction. Clostridium Difficile (CD) usually is present in the gut of healthy subjects without giving any disease. As a consequence of various stress, including antibiotic therapy, $C D$ can replicate and produce $A$ and $B$ toxins that induce diarrhoea. The finding of $A$ and $B$ toxins is a landmark for diagnosis of CD infection.

Methods. 60 stool samples have been tested for CD presence. All the samples have been tested for the glutamate dehydrogenase (GDH) presence. The GDH positive samples have been tested with two rapid tests to evidence $A$ and $B$ toxins. Moreover, 18 positive and 3 negative GDH samples have been examined by means of cultivation tests and using two nested PCR ( $\mathrm{n}-\mathrm{PCR}$ ) commercial kits (Neomed, Rho, Italy) to amplify the CD toxin coding gene $t c d C$ and $t c d B$.

Results.Among 60 examined samples, 52 (45\%) were GDH positive, and, among these, 46 (76\%) and 37 (62\%) resulted respectively positive for both $A B$ and for only $A C D$ toxin using screening tests. Among the $18 \mathrm{GDH}$ positive samples tested, I4 were positive for tcdC and tcdB $\mathrm{n}$-PCR, while all the $3 \mathrm{GDH}$ negative samples were confirmed as negative. The isolation in colture was positive in 16 of the GDH positive and in 2 of the $3 \mathrm{GDH}$ negative samples.

Conclusions. These data suggest that the GDH test is a useful screening method that must be associated to a confirmatory assay. The search of $C D$ toxin coding gene by $n-P C R$ seems to be a sensitive and specific method to assess the infection with toxins producing CD.

\section{INTRODUZIONE}

Clostridium difficile (CD) è un batterio anaerobio Gram positivo, sporigeno, presente nell'ambiente, che può ritrovarsi nell'intestino di soggetti adulti sani e neonati, in cui raramente causa patologie. A seguito di terapie antibiotiche, CD può moltiplicarsi rapidamente e iniziare a produrre tossine, causa di malattia. Le tossine prodotte, A e B, responsabili dei danni alla mucosa intestinale, sono alla base dei test diagnostici di screening. Le tossine A e B sono codificate rispettivamente dai geni $t c d A$ e $t c d B$, collocati all'interno della regione PaLoc in cui sono presenti anche un gene (tcdE) per una porina e i geni regolatori $t c d D$ e $t c d C$. Alcuni studi hanno dimostrato che, in caso di polimorfismi o delezioni nell'ambito del gene tcdC viene a mancare il controllo negativo dell'espressione delle tossine, la cui produzione così risulta molto incrementata $(1,5)$.

È stato osservato che molti pazienti possono risultare positivi ai test di screening per la presenza di tossine ma essere asintomatici, suggerendo che la presenza delle tossine A e B non è predittiva al $100 \%$ della manifestazione clinica e viceversa. Inoltre è stato osservato che alcuni ceppi non producono la tossina $\mathrm{A}$, ma solo la $\mathrm{B}$, confermando la presenza di differenti ceppi virulenti di CD (3).

Per la diagnosi d'infezione, il saggio di citotossicità sulle tossine è ancora considerato il gold-standard, anche se la coltura batterica riesce ad evidenziare quasi un terzo di casi in più: tuttavia, entrambi gli approcci hanno perso importanza sul piano clinico. Infatti, nonostante i metodi di coltura batterica siano molto sensibili (90-100\%) e consentano di applicare i processi di tipizzazione per le analisi epidemiologiche, richiedono un significativo carico di lavoro per il personale laboratoristico, hanno un lungo turn-around time (circa 72 ore) che li rende impraticabili nei casi di urgenza e, soprattutto, non sono in grado di evidenziare se il ceppo coltivato è produttore di tossine o meno.

Pertanto, molto spesso si utilizzano test mirati esclusivamen- te all'evidenziazione delle tossine di CD in presenza di glutammato deidrogenasi (GDH), utilizzando saggi immunoenzimatici rapidi. Esistono in commercio test in grado di riscontrare entrambe le tossine e altri capaci di rilevare solo la tossina A. Si tratta di test abbastanza semplici, con una sensibilità accettabile (80-95\%) e con un breve turn-around time (2 ore), che ne favorisce l'utilizzo in urgenza. Un'importante limitazione di quest'approccio è che i kit che rilevano esclusivamente la tossina A possono dare dei falsi negativi, nei casi sostenuti da ceppi produttori di solo tossina B. Inoltre, falsi negativi si possono avere anche nei casi in cui i ceppi batterici producono solo bassi quantitativi di tossine e quindi non raggiungono la soglia di determinabilità del test stesso. Per aumentare la sensibilità dei risultati dei test di screening e dei test rapidi per la ricerca delle tossine, nel nostro laboratorio abbiamo deciso di provare dei test di biologia molecolare, in quanto dati presenti in letteratura dimostrano che la PCR eseguita sul campione fecale ha una sensibilità superiore a quella della metodica EIA. Inoltre la PCR possiede un buon turn-around time (meno di 4 ore) e può essere utilizzata per dare risposte in urgenza.

\section{MATERIALI E METODI \\ Campioni}

Sessanta campioni di feci di pazienti (42 donne, 18 uomini, età compresa tra 24 e 86 anni) con diarrea, giunti al Laboratorio di Microbiologia dell’Ospedale San Giuseppe, sono stati analizzati per la ricerca d'infezione da CD.

\section{Metodi di screening e tradizionali}

Inizialmente, tutti i campioni sono stati analizzati con il kit per la determinazione dell'enzima glutammato deidrogenasi (GDH, C. DIFF QUIK CHEK, Inverness Medical, Italy). I campioni positivi sono stati poi sottoposti a due test rapidi per la ricerca delle tossine: quello per la ricerca della sola tossina A (TOX A, BSN, Italy) e quello per la ricerca di entram-

\section{Corresponding author: Rita Caldarelli}

Laboratorio Analisi, GB Mangioni Hospital

Via Leonardo Da Vinci 49; 23900 Lecco - Tel.: 034I478282 - Fax: 034I285087

E-mail: caldarellirita@hotmail.com 
be le tossine (TOX A/B QUIK CHEK, Inverness Medical, Italy). Successivamente, 18 campioni positivi al test GDH e 3 campioni negativi (di pazienti con un quadro clinico suggestivo per un'infezione da CD), sono stati analizzati anche con metodi di microbiologia classica, ovvero coltura sia su terreno CCYE (Oxoid, Italy) con uovo (secondo la BSOP ID8, edizione Italiana, dell’NHS-National Public Healty Service), sia su CD agar selective (Oxoid, Italy), contenente sangue. Tutti i campioni sono stati sottoposti a shock alcolico.

\section{Test di biologia molecolare}

Sono stati inizialmente testati tre diversi metodi di estrazione di DNA dalle feci:

- Rapid DNA extraction-B (Neomed, Italy),

- FTA elute microcards (Wathman, Neomed, Italyl),

- QG DNA tissue extraction con il sistema semi-automatico

QG Mini-80 (Fuji, Neomed, Italy).

I tre metodi si sono rivelati equivalenti per qualità di DNA estratto, anche se con purezza ed efficienza diverse (dati non mostrati). Per facilità e rapidità di metodo è stato utilizzato il kit Rapid DNA extraction-B.

I 18 campioni di feci positivi ed i 3 negativi al test GDH sono stati analizzati mediante nested-PCR (sia prima che dopo essere stati sottoposti a shock alcolico), utilizzando due diversi kit commerciali entrambi della ditta Neomed (Neomed, Rho, Italia). Il primo kit (TCDC DNA, n-PCR) è stato disegnato in modo da amplificare il gene $t c d C$, che regola la produzione di entrambe le tossine, e nell'altro il solo gene $t c d B$ (TCDB DNA, n-PCR), che produce la tossina B.

Come controllo positivo è stato utilizzato il ceppo di CD tossigenico ATCC 9689 (Microbiologics).

\section{RISULTATI}

Tra i 60 campioni analizzati 52 (86\%) erano positivi al test per la ricerca di GDH, mentre 46 (76\%) sono risultati positivi con il test EIA per entrambe le tossine A e B, e 37 (62\%) per la sola tossina A (Tabella 1), dimostrando che anche nella nostra regione circola il ceppo A-/B+.

Non tutti i campioni positivi per GDH sono inoltre risultati positivi in n-PCR o in coltura. Infatti, come si può vedere nella Tabella 2, sono stati analizzati 21 campioni mediante nPCR (18 positivi al test GDH e 3 negativi), e sono risultati positivi all'amplificazione del gene tcdC 14 (67\%) dei 18 campioni GDH positivi, mentre i 3 campioni GDH negativi sono risultati negativi anche in PCR. Risultati del tutto sovrapponibili sono stati ottenuti utilizzando il kit per l'amplificazione del gene $t c d B$ del CD.

Allo scopo di valutare l'effetto del trattamento mediante shock alcolico sui risultati dell'amplificazione genica, i 21 campioni già testati al GDH sono stati testati con n-PCR anche dopo trattamento. I risultati sono di particolare interesse, in quanto sia per la regione $t c d C$ che $t c d B$ si è ottenuto un incremento di positività, suggerendo che in questi pazienti il CD tossigenico probabilmente era stato eliminato, ma erano probabilmente ancora presenti le spore (Tabella 1).

Le colture in CCYE e agar selettivo per CD hanno dato risultati simili, con 16 (89\%) dei campioni GDH+ positivi anche in coltura, ma con 2 (67\%) dei tre campioni GDH- positivi in coltura.

\section{CONCLUSIONI}

L'alto numero di soggetti positivi al test per la produzione di GDH (e negativi per la produzione di tossine), indica che questo test non è propriamente specifico, ma può comunque rappresentare un test di screening preliminare. A questo test deve però essere associato un altro test sensibile, specifico e rapido, come potrebbe essere la ricerca del DNA di CD mediante PCR, per la conferma di infezione, così come suggerito anche ì da diversi autori e dalle linee guida europee $(2,6)$.

Dai nostri dati non emerge differenza nei risultati in PCR tra la regione del gene $t d c B$ e quella del gene $t c d C$, anche se recentemente le linee guida europee suggeriscono di amplificare a scopo diagnostico la regione del gene $t d c B$, che controlla la produzione della tossina $\mathrm{B}$, piuttosto che il gene tcdC, che controlla la produzione di entrambe le tossine. È stato osservato infatti da più autori che questa regione può presentare anche lunghe delezioni, che quindi potrebbero compromettere il risultato finale della PCR (5).

Per incrementare la sensibilità della reazione di n-PCR è evidente che sarebbe consigliabile sottoporre i campioni a trattamento alcolico, per permettere la rivelazione delle spore presenti nel campione.

Infine, i risultati suggeriscono che potrebbe essere utile associare la coltura nei campioni di pazienti clinicamente suggestivi per infezione da CD, nonostante sia una procedura che richiede tempo per ottenere risultati, tenendo tuttavia conto del fatto che la crescita in coltura del CD non da' informazioni sulla produzione di tossine.

Tabella I. Risultati della ricerca di GDH e dei due test rapidi per la rivelazione delle tossine del CD in 60 campioni

\begin{tabular}{lccc}
\hline \multicolumn{4}{l}{ Tabella I. Risultati della ricerca di GDH e dei due test rapidi per la rivelazione delle tossine del CD in 60 campioni } \\
\hline GDH (\%) & TOX A/B (\%) & TOX A (\%) \\
\hline positivi & $52(86)$ & $46(76)$ & $37(62)$ \\
\hline negativi & $8(14)$ & $14(24)$ & $23(38)$
\end{tabular}

Tabella 2. Risultati della ricerca mediante nested-PCR delle regioni tcdC e tcdB nei campioni preliminarmente analizzati al test GDH, senza trattamento alcolico e dopo trattamento alcolico delle feci, in confronto ai risultati del test GDH e della metodica colturale.

\begin{tabular}{|c|c|c|c|c|c|c|}
\hline & \multirow{2}{*}{ GDH } & \multicolumn{2}{|c|}{ Senza trattamento alcolico } & \multicolumn{2}{|c|}{ Dopo trattamento alcolico } & \multirow{2}{*}{ Test coltural } \\
\hline & & n-PCR tcdC (\%) & $n-P C R$ tcdB (\%) & $n-P C R$ tcdC (\%) & $n-P C R$ tcdB (\%) & \\
\hline positivi & 18 & II (6I) & $I I(6 I)$ & $\mid 4(77)$ & $14(77)$ & $16(89)$ \\
\hline negativi & 3 & 0 & 0 & 0 & 0 & $2(67)$ \\
\hline
\end{tabular}

\section{BIBLIOGRAFIA}

1. Dupuy B, Govind R, Antunes A, Matamouros S. Clostridium difficile toxin synthesis is negatively regulated by TcdC. Jour of Med Microb 2008; 57: 685-9.

2. Fenner L, Widmer AF, Goy G, Rudin S, Frei R. Rapid and reliable diagnostic algorithm for detection of Clostridium difficile. Jour of Clin Microb, 2008; 46: 328-30.

3. Lyerly DM, Barroso LA, Wilkins TD, Depitre C, Corthier G Characterization of a toxin A-negative, toxin B-positive strain of Clostridium difficile. Infect and Immun 1992; 60: 4633-9.

4. Sloan M, Duresko BJ, Gustafson DR, Rosenblatt JE. Comparison of Real-
Time PCR for Detection of the $t c d C$ Gene with four toxin immunoassays and culture in diagnosis of Clostridium difficile Infection. Jour of Clin Microb 2008; 46: 1996-2001.

5. Spigaglia P, Mastrantonio P. Molecular analysis of the pathogenicity locus and polymorphism in the putative negative regulator of toxin production $(\mathrm{TcdC})$ among Clostridium difficile clinical isolates. Jour of Clin Microb 2002; 40: 3470-5.

6. Crobach MJ, Dekkers OM, Wilcox MH, Kuijper EJ. European Society of Clinical Microbiology and Infectious Diseases (ESCMID): data review and recommendations for diagnosing Clostridium difficile-infection (CDI).Clin and Microb Infect 2009; 15: 1053-66. 